\title{
Liberdade, responsabilidade moral e justiça eterna em Schopenhauer
}

Freedom, moral responsibility and eternal justice in Schopenhauer

\section{Aguinaldo Pavão*}

Resumo: Para Schopenhauer, a liberdade moral não pode ser entendida como um poder que o homem teria de, a cada ação, decidir agir de um modo ou de outro com base em sua própria vontade. Embora as ações humanas estejam submetidas à mais estrita necessidade, a responsabilidade é possível haja vista que a vontade do homem como coisa em si, seu caráter inteligível, é livre. Além disso, Schopenhauer defende que o mundo é regido pela justiça eterna. De acordo com essa noção, a atribuição de responsabilidade moral ao atormentador pelos sofrimentos que causa ao atormentado prende-se a uma diferença que não atinge a coisa em si. Algoz e vítima são unos, visto que a vontade vive em ambos. Nesse artigo, exploro esses pontos para tentar mostrar o insucesso de Schopenhauer ao procurar elucidar os juízos de responsabilidade moral.

Palavras-chave: Liberdade; Responsabilidade; Vontade; Justiça eterna

Abstract: According to Schopenhauer, moral freedom cannot be understood as a power that man would have, at every action, to decide to act in one way or another on the basis of his own will. Although human actions are subject to the strictest necessity, responsibility is possible since man's will as a thing in itself, its intelligible character, is free. Moreover, Schopenhauer argues that the world is governed by eternal justice. According to this notion, the attribution of moral responsibility to the tormentor for the sufferings he causes to the tormented is linked to a difference that does not affect the thing itself. Tormentor and the victim are one, since the will lives in both. In this article, I explore these points to try to show Schopenhauer's failure to elucidate judgments of moral responsibility.

Keywords: Freedom; Responsibility; Will; Eternal justice

\section{Introdução}

No início de Sobre a liberdade da vontade, Schopenhauer sustenta que o conceito de liberdade, em seu sentido físico, implica o reconhecimento de que homens e animais são considerados livres quando nada obstaculiza suas ações, isto é, quando eles podem agir sem que laços, prisões ou paralisias os detenham. Em suma, quando nenhuma oposição física ou material impede que suas ações ocorram de acordo com suas vontades (E I, 32). Ao que tudo indica, o reconhecimento da liberdade física permite a admissão da liberdade de ação. Nesse caso, parece coincidirem as posições de dois célebres compatibilistas, Hobbes

\footnotetext{
* Professor do Departamento e do Programa de Pós-Graduação em Filosofia da Universidade Estadual de Londrina (UEL). E-mail: aguinaldo.pavao@uol.com.br
} 
e Hume, com a de Schopenhauer ${ }^{1}$. Haveria assim lugar na teoria Schopenhauer para a assimilação compatibilista da liberdade à necessidade ou da liberdade ao determinismo. Será realmente esse o caso?

A resposta para essa pergunta não apresenta maiores dificuldades. Ela consiste em perceber que a liberdade da ação admitida não envolve nada de moralmente relevante. Quando Schopenhauer discute a liberdade moral, ele nega a liberdade da ação. Pode-se dizer que a liberdade da ação só vale em termos físicos, sem relevância para a discussão moral. Ora, esse não é o caso de Hobbes e Hume. Eles assumem consequências morais quando afirmam a liberdade de ação e negam a liberdade da vontade. A responsabilidade moral não requer a liberdade da vontade nesses autores, o que não é o caso de Schopenhauer. Sendo assim, sinto-me autorizado a afirmar que a comitiva de predecessores de Schopenhauer, destacada no capítulo 4 de Sobre a liberdade da vontade, representa uma comitiva de antecessores e aliados num aspecto que tem relevância moral menor, pois a contribuição deles é meramente negativa, isto é, eles (especialmente Hobbes, e $\mathrm{Hume}^{2}$ ) não são autênticos aliados de Schopenhauer quando se trata de pensar a noção de responsabilidade moral. Na verdade, penso que, num sentido mais rigoroso, tendo em vista a compreensão unidimensional que eles adotam, Hobbes e Hume acabam subtraindo as bases da responsabilidade moral.

Schopenhauer, assim, pode até ser considerado um compatibilista se pensarmos apenas na liberdade física e na intelectual, porém, como essas duas formas de liberdade não garantem a imputação moral, ele não é um compatibilista quando pensamos, como se costuma fazer, que o compatibilismo diz respeito à compatibilidade entre a existência de agentes livres e moralmente responsáveis e o determinismo natural. Uma declaração no capítulo 5 de Sobre a liberdade da vontade deixa claro o fato de Schopenhauer não se alinhar com compatibilistas de índole análoga a de Hobbes e Hume.

A liberdade não é removida pela minha exposição, mas apenas deslocada do domínio das ações individuais, onde é demonstrável que não pode ser encontrada, para uma região superior, não tão fácil de acessar para a nossa cognição: ela é transcendental (E I, 109).

\footnotetext{
${ }^{1}$ Cf. HOBBES, Thomas. Hobbes's Treatise of Liberty and Necessity. In: Hobbes and Bramhall on Liberty and Necessity; HOBBES, T. Leviathan., chap. 21, p. 139-140; HUME, D. An Enquiry concerning Human Understanding, section 8, p. 148-164; HUME, D. A Treatise of Human Nature, Book II, part III, sections 1-2, p. 257-261.

${ }^{2}$ Schopenhauer cita diversos autores, entre os quais Kant, o qual, porém, representa um caso à parte. Digo isso porque Kant faz uma defesa transcendental da liberdade, não aceitando, assim, soluções unidimensionais para a responsabilidade moral. Em outras palavras, Kant compreende a liberdade a partir da distinção transcendental entre fenômeno e coisa em si. Dessa forma, Kant representa, se não exatamente um predecessor, certamente o maior inspirador da visão de Schopenhauer sobre o tema da liberdade e responsabilidade moral.
} 
Sobre seu não alinhamento com os compatibilistas, cabe citar ainda a seguinte passagem dos Parerga:

Depois de meu ensaio premiado sobre a liberdade moral nenhuma pessoa pensante pode ainda duvidar de que esta não deve ser buscada de modo algum na natureza, mas unicamente fora dela. A liberdade moral é algo metafísico, impossível, porém, no mundo físico (PP II, Sobre ética, § 116, 70).

Vale destacar a postura profundamente consequente de Schopenhauer com relação à tese da não liberdade moral das ações (isso precisa ser computado como um de seus notáveis méritos) ${ }^{3}$. Embora, como indicado, ele se alinhe ao compatibilismo de Hobbes e Hume, colocando esses filósofos como seus predecessores, uma vez que, como eles, assume o determinismo dos eventos naturais, ele também assume o determinismo das ações com a coerente consequência de que esse determinismo subtrai a liberdade (moral) delas ${ }^{4}$, o que insisto - Hobbes e Hume não fizeram. Se o mundo dos fenômenos se refere tão somente ao conhecimento, regido pelo princípio de razão, a necessidade precisa ser admitida sem reservas. Ora, admitida a necessidade de tudo o que ocorre, temos de admitir, se quisermos ser coerentes, a impossibilidade de ações verdadeiramente livres, isto é, temos de aceitar que ações livres não podem ter lugar no mundo considerado apenas do ponto de vista da representação. Ora, a liberdade no sentido moralmente relevante implica negação da necessidade. Logo, deve ela ser encontrada e reconhecida em outro domínio, ou declarada impossível. Mas, como a citação acima deixa claro, Schopenhauer de modo algum sugere ser a liberdade moral das ações algo impossível ou quimérico.

Antes de prosseguir, gostaria de abrir um parêntese. Preciso registrar que não é meu objetivo nesse texto recuperar teses gerais da cosmologia schopenhaueriana e tampouco discutir teses interpretativas sobre se o mundo como vontade e como representação seria apenas um duplo ponto de vista, ou envolveria algo de cunho ontológico quando considerado como vontade. Uso a expressão "ponto de vista” a partir do que se pode ler, por exemplo, em O mundo, tomo I, § 27 e $\S 71$.

O que em si é vontade existe de outro ponto de vista como representação, ou seja, é aparência [was an sich Wille ist, ist andererseits als Vorstellung da, d.h. ist Erscheinung] (W I, § 27, 203).

\footnotetext{
${ }^{3}$ Compreenda-se a rejeição da tese da não liberdade moral das ações não em virtude do determinismo delas, o que Schopenhauer sustenta, mas em virtude de as ações refletirem a liberdade moral do caráter inteligível (operari sequitur esse). A liberdade não pertence às ações, mas à vontade, ao caráter inteligível. Cabe notar, porém, que ao me referir ao mérito, penso na consistência interna do pensamento de Schopenhauer, isto é, levo em conta a coerente acomodação dos três tipos de liberdade. Mais para a frente, pretendo destacar duas críticas externas à sua visão, a saber, sobre a autocompreensão do sujeito moral e acerca da justiça eterna. ${ }^{4} \mathrm{O}$ que implica dizer: subtrai as bases da responsabilidade moral.
} 
Esta vontade e este mundo são justamente nós mesmos, e a ele pertence à representação em geral como um de seus lados: a forma desta representação é espaço e tempo, de modo que, deste ponto de vista [für diesen Standpunkt], tudo o que existe tem de estar em algum lugar e num dado tempo (W I, § 71, 517).

Pois bem, que Schopenhauer se comprometa com a tese da necessidade das ações, parece não pairar dúvidas. Ainda assim, abonos são sempre bem-vindos. Em Sobre a liberdade da vontade encontramos explicitamente a alegação segundo a qual é preciso remover "inteiramente a liberdade das ações humanas, reconhecendo-as como completamente subordinadas à necessidade mais estrita” (E I, 105) 5 .

Acredito, todavia, que o raciocínio de Schopenhauer, embora faça sentido em grandes linhas, apresenta um embaraço incontornável para a elucidação dos juízos de reponsabilidade moral. Explico-me. Um juízo de responsabilidade moral somente é possível quando podemos afirmar que determinada ação praticada pode ser imputada ao agente. Esse, por sua vez, precisa ser entendido como um ser livre do qual promana a ação a ele atribuída (como um feito seu) ${ }^{6}$, portanto um agente entendido como autor no sentido forte, que poderia ser chamado de uma causa livre e, assim, jamais um mero elo numa cadeia causal.

Pergunto, porém, ao leitor desse texto: você acredita que está exercendo agora sua liberdade, que está sendo livre lendo esse artigo? Imagino que seria muito razoável afirmar que sim. Você está livremente dedicando sua atenção a essas linhas, pois se quisesse poderia interromper a leitura. Você é livre porque depende de você não apenas fazer o que quer fazer, mas poder, se quiser, não fazer o que está fazendo. E afirmar que esse "se

\footnotetext{
${ }^{5}$ No mesmo sentido, ver: E II, $\S 10,91$. Vale lembrar que a tese da necessidade do agir individual perpassa todo o importante $\S 55$ do tomo I de O mundo.

${ }^{6}$ Essa é aproximadamente a compreensão de Kant. Na introdução à Metafísica dos costumes, Kant afirma: "Imputação no sentido moral é o juízo por meio do qual alguém é considerado como autor (causa libera) de uma ação, que, pois, chama-se feito (factum) e está sob leis” (KANT, I. Metafísica dos costumes, p. 33). Acredito que, nesse sentido geral, Schopenhauer concordaria com Kant, visto que para o autor de O mundo o operari é imputado ao esse, que é livre. Estou, porém, ciente de que a discussão sobre causalidade e liberdade em Schopenhauer não segue o pensamento de Kant, sendo, na verdade, interditada em virtude da compreensão segundo a qual a causalidade somente pode valer para a representação, jamais para a vontade como coisa sem si. Vale destacar que acima apenas registro um pressuposto geral de minha compreensão sobre a reponsabilidade moral. Não se trata, pois, nesse caso, da apresentação do pensamento de Schopenhauer sobre o tema. A propósito, para quem quiser ter contato com uma instigante discussão sobre a liberdade em Kant e Schopenhauer e ponderar uma compreensão divergente da que aqui se defende, recomendo a leitura de: DEBONA, Vilmar. Caráter, liberdade e Aseität: sobre a assimilação das noções de caráter inteligível e caráter empírico de Kant por Schopenhauer, pp. 32-50.
} 
quiser” depende de você significa dizer que depende da sua vontade. Não seria um abuso glosar essa última frase assim: depende da decisão que você tomar. Você pode decidir prosseguir a leitura ou abandoná-la. Você controla a ação (ou se quiser, acredita que controla ${ }^{7}$ ). E você presumivelmente faz isso não apenas como alguém que continua lendo porque quer, sendo indiferente ao fato de, por exemplo, poder sair da cabine de estudos da biblioteca e ir tomar água no bebedouro a 10 metros de distância. Não me parece possível sermos indiferentes em nossa autocompreensão de sujeitos livres com respeito ao fato de alternativas de ação estarem em nosso poder.

Schopenhauer, quando saía para passear com o lendário poodle Atma, acreditava que sua ação não era livre? Ele acreditava, antes de pôr o pé na rua com seu cão, que certos motivos se apresentavam e que ele, tendo tal caráter, não poderia fazer outra coisa do que passear em tal horário com o amável Atma? Se fosse assim, parece que ele propriamente não agia, mas algo nele agia, os motivos e o caráter como causas do passeio com o poodle. Digo que algo agia nele e não ele propriamente, pois a ideia de que os motivos não possam ser reconduzidos à nossa individualidade moral parece pacífica - com efeito, eles comportam sempre uma exterioridade em relação a nosso ser moral. "Todos os motivos são causas e toda causalidade traz consigo necessidade” (E I, 57). Já o mesmo, aparentemente, não pode ser dito do caráter. Poder-se-ia dizer que ele se confunde com nosso próprio "eu moral”.

Antes de avançar e abordar o tema do nosso ser em si moral, vale registrar que Schopenhauer aproxima-se muito do reconhecimento da procedência da alegação que venho fazendo. Com efeito, ele diz:

como é o querer livre que se torna visível na pessoa e em toda a sua conduta, estando para esta como o conceito está para a definição, segue-se que cada ação isolada do ser humano deve ser atribuída à vontade livre e também se apresenta imediatamente enquanto tal à consciência: eis por que cada um de nós [...] considera a si mesmo a priori (vale dizer, segundo seu sentimento originário) livre, inclusive nas ações particulares, no sentido de em qualquer caso dado ser possível qualquer ação, porém só a posteriori, a partir da experiência e da reflexão sobre ela, reconhece que seu agir foi produzido de modo completamente necessário a partir do confronto do caráter com os motivos (W I, § 55, 374).

Há algumas dificuldades em torno dessa passagem. Primeiro, Schopenhauer, logo na sequência, desconsidera esse sentimento dizendo que seguir esse sentimento originário seria próprio de uma pessoa tosca. Em segundo lugar, ele não admite que eu possa licitamente considerar que poderia ter agido de modo diferente. Ele aceita o sentimento de que, ao agir, penso que posso agir de modo diferente. Ademais, Schopenhauer em Sobre a

\footnotetext{
${ }^{7}$ Mais para a frente vou me deter no ponto sobre a crença na liberdade da vontade ao agir.
} 
liberdade da vontade não consagra relevância ao sentimento de liberdade da ação, mas ao sentimento de responsabilidade. É o sentimento de responsabilidade que pode com legitimidade servir de sustentação para se afirmar a liberdade (cf. E I, 105). Nesse sentido, também é importante destacar que, para Schopenhauer, há uma diferença capital entre (i) tentar apoiar a liberdade da vontade individual num sentimento e (ii) tentar fundá-la na autoconsciência.

Este último tópico, sobre o possível fundamento da liberdade da vontade na autoconsciência, é tratado em detalhes por Schopenhauer em Sobre a liberdade da vontade. Para ele, resumidamente, a autoconsciência é incapaz de fazer um pronunciamento válido sobre se nossa vontade é livre para querer o que quer. A autoconsciência consegue licitamente apenas afirmar que "posso fazer o que quero" (E I, 41). E, como indiquei acima, Schopenhauer corretamente considera isso insuficiente em termos morais, pois, sob o ponto vista moral, não basta admitir a liberdade física e intelectual ${ }^{8}$.

Vale insistir nessa ideia: em que pese a negação da liberdade das ações, Schopenhauer, como defensor da validade dos juízos de responsabilidade moral, defende, coerentemente, a existência da liberdade moral (por ele chamada de "verdadeira liberdade moral" [wahre moralische Freiheit], que não se confunde com a doutrina do livre arbítrio). Não se trata mais de pensar apenas em motivos, uma causalidade em última instância física, mas de considerar o nosso caráter inteligível, pois é ele que confere significado metafísico à noção de autoria moral ${ }^{9}$ sem a qual os juízos responsabilidade seriam tão somente atos verbais. Nessa perspectiva, cabe assinalar que Schopenhauer sustenta que somos autênticos autores de nossas ações, não apenas porque operari sequitur esse, mas, mais profundamente, porque

tão somente se a essência íntima do ser humano é sua própria vontade, por conseguinte, apenas se ele, no sentido mais estrito do termo, é sua própria obra, são seus atos exclusivamente seus e assim são-lhes imputáveis. Por outro lado, se o ser humano tem uma origem outra ou é obra de um ser diferente de si mesmo, toda a sua culpa recai sobre essa origem ou autor (W II, cap. 47, 704).

Essa importante tese do capítulo 47 dos Suplementos já havia sido apresentada no $\S$ 55 do tomo I de $O$ mundo, embora sem referência expressa à imputação. No tomo I, Schopenhauer havia dito que o "homem é a sua própria obra antes de todo conhecimento"

\footnotetext{
${ }^{8}$ A liberdade intelectual é aquela que o indivíduo goza quando sua faculdade cognoscitiva funciona sem perturbações constantes ou passageiras e quando as circunstâncias externas não falsificam a apreensão dos motivos. Por exemplo, se o intelecto está acometido por loucura, delírio ou convulsões, ele perde sua liberdade intelectual, assim como perde alguém que serve veneno pensando ser um remédio ou confunde um membro da casa com um ladrão e atira contra ele (cf. E I, 110).

${ }^{9}$ O sentido da expressão "autoria moral" está, aqui, destituído de qualquer ingrediente do direito positivo, ou melhor, é independente do direito positivo brasileiro ou de qualquer outro país.
} 
(W I, § 55, 379). Essa parte em que se lê "antes de todo conhecimento" dá ensejo à pergunta singela: como posso ser obra de mim mesmo antes de todo conhecimento? Como posso escolher ser isto ou aquilo sem conhecimento? Eu não dispunha de alternativas rivais para decidir ser quem eu sou? Se eu sou minha própria obra, que tipo de artífice de mim mesmo eu sou?

Deve-se conceder que o conhecimento do que se é, ainda que não pleno, joga luz na possível autocompreensão do sujeito moral como autor de suas ações. Se, com o tempo, chego a conhecer que minha índole moral é egoísta num grau acentuado, torna-se mais fácil entender que as ações injustas que realizo e a indiferença que sinto em relação ao sofrimento alheio são minhas, pois estampam, como num selo, o carimbo de um caráter inteligível moralmente deficiente em termos morais ${ }^{10}$.

Quando pensamos em decisão, pensamos em ponderação de alternativas rivais. Ao terminar de escrever esse texto, ou ao suspender sua escrita para um descanso, posso fazer um pequeno passeio com minhas filhas ou ir à cozinha preparar mais um café para logo voltar a essas linhas (entre outras alternativas, claro). Para tanto, preciso entender o que significa fazer um passeio com minhas filhas ou preparar um café. Ou seja, é preciso, para acreditar que exerço essa liberdade, ter algum conhecimento das alternativas disponíveis (não posso, como ser humano, guiar minha conduta sem o auxílio de conceitos, sendo, pois, decisiva a liberdade intelectual). E quando decido ser o ser moral que sou, eu decido com base em algum conhecimento de alternativas possíveis? No primeiro caso, de acordo com Schopenhauer, não - o caso das ações, pois nelas impera o determinismo. A rigor, no caso do meu agir, a decisão é assistida por mim, ou dito de forma mais franca, a decisão é tomada em mim, mas não por mim $^{11}$. Talvez se possa conceder isso às ações (façamos essa concessão para argumentar). Mas e no segundo caso, no caso em que eu sou minha própria obra $^{12}$ ? Como entender a decisão, se é que há uma, com respeito a eu ser quem sou? Essa pergunta tem, por certo, uma importância crucial para entendermos a moralidade desse ser

\footnotetext{
${ }^{10}$ Tenho em mente aqui a famosa passagem de Schopenhauer segundo a qual o caráter inteligível do homem está "presente [...] em todos os [seus] atos [...] e impresso em todos eles, como o carimbo em mil selos" (E II, § 10, 89).

11 "A decisão propriamente dita é por ele [intelecto] esperada de modo tão passivo e com a mesma curiosidade tensa como se fosse a de uma vontade alheia” (W I, § 55, 377).

${ }^{12}$ Esse é caso, como quer Schopenhauer, em que sou portador de asseidade (Aseität). Se devesse minha existência a um outro ser, não seria livre. Para Schopenhauer, não há como sustentar que seres moralmente responsáveis sejam criaturas, isto é, obras de um outro ser (eis um dos erros fatais do teísmo). "Liberdade moral e reponsabilidade ou imputabilidade simplesmente pressupõem ASSEIDADE. As ações sempre provêm necessariamente do caráter, isto é, da constituição própria e, portanto, inalterável do ser, sob a influência dos motivos e de acordo com eles. Por conseguinte, se esse indivíduo tiver de ser responsável, precisa existir originariamente e em virtude de sua própria plenitude de poder" (P I, Fragmentos sobre história da filosofia, p. 179). Veja também: N, 210; PP II, Sobre a ética, § 118, 81; W II, cap. 25, 385-386, W II, cap. 47, 704.
} 
que é autor de si mesmo. E não acredito que ajude a esclarecer a afirmação de que "nosso caráter deve ser visto como o desdobramento temporal de um ato extratemporal, portanto, indivisível e imutável da vontade" (W I, § 55, 389). Com efeito, há necessidade de mais detalhes sobre o que pode vir a significar "ato extratemporal da vontade". Como devemos entendê-lo? Ora, não se encontra em Schopenhauer os pormenores sobre o significado dessa expressão. Se pensarmos em jogar alguma luz afirmando que se trata de uma metáfora, de um recurso último da linguagem, não logramos êxito. Ao menos eu não entendo o que possa vir a significar alguém responder moralmente por algo que não fez, não escolheu, por algo que não é seu ato no sentido comum do termo, isto é, o fazer ou agir intencional próprio dos seres humanos ${ }^{13}$.

A meu ver, o sentimento de que somos livres ao agir, mesmo que tenha um fundo filosófico frágil ${ }^{14}$, é constitutivo de nossa autocompreensão. Insisto sobre esse ponto, ao qual já me referi antes ao falar sobre a autocompreensão do sujeito e da aparente impossibilidade de sermos indiferentes à existência de alternativas rivais para os cursos de ação que adotamos. Nesse contexto, julgo oportuno chamar a atenção para a passagem em que Schopenhauer, ainda considerando uma ilusão a liberdade do agir e do querer individual, isto é, considerando essa autocompreensão como ilusória, a qualifica de natural. Vejamos.

'Posso fazer o que quero', que nós examinamos extensamente no primeiro capítulo, algo que ouvimos especialmente quando vários motivos exercem influência entre si por solicitações e exclusões recíprocas. Então, tudo isso em conjunto é a fonte da ilusão natural [natürlichen Täuschung], pela qual floresce o erro de que em nossa autoconsciência há a certeza de uma liberdade de nossa vontade, no sentido de que, contrariamente a todas as leis do entendimento puro e da natureza, está algo que decide sem razão suficiente, e que suas decisões, em dadas circunstâncias, poderiam resultar nesta direção ou em outra direção oposta em um e mesmo homem (E I, 62).

Mesmo que seja uma ilusão natural [natürlichen Täuschung], a crença na liberdade do agir e do querer individual tem de ser acolhida na elucidação dos juízos de responsabilidade moral. Interpreto, assim, a ilusão natural a que Schopenhauer faz referência como uma ilusão necessária, constitutiva de autocompreensão que os seres humanos têm de si mesmos. O acolhimento da crença na liberdade do agir e do querer individual é decisivo sobretudo quando se trata de pensar a autoatribuição de reponsabilidade. Nesse sentido, poderia parecer mais aceitável se essa ideia fosse

\footnotetext{
${ }^{13}$ Assim sendo, não vejo razões para adotar aqui um pensamento diferente daquele defendido em PAVÃO, Aguinaldo. "Liberdade e imputação moral em Schopenhauer". In: Schopenhauer: metafísica e moral.

${ }^{14}$ Frágil significa aqui apenas a impossibilidade de obtenção de uma prova demonstrativa ou com evidências empíricas robustas. Talvez tenhamos apenas, se eu estiver certo, uma base psicológica forte para a atribuição da liberdade também ao agir (a autocompreensão do sujeito agente).
} 
restringida à primeira pessoa (o agente), sem estendê-la à terceira pessoa (o observador). Defendo, porém, que se estou, de alguma forma, autorizado a considerar a mim mesmo responsável por me julgar capaz de agir e querer livremente, devo, por analogia, aplicar o mesmo para outros seres humanos.

$\mathrm{Na}$ linha dessas reflexões, outro ponto merece atenção. Schopenhauer confia no sentimento de responsabilidade, considerando-o perfeitamente claro e seguro (E I, 105). Para ele, o sentimento de responsabilidade autentica a legitimidade da tese de que eu sou o autor de minhas ações, sendo tal sentimento o único dado que pode garantir a liberdade moral e a consequente imputação das ações ao caráter do homem (cf. E I, 106). Ora, por que confiar apenas no sentimento de responsabilidade e não confiar no sentimento de liberdade? Não seria igualmente possível considerar ilusório também o sentimento de reponsabilidade? Talvez. É importante frisar, contudo, que a perspectiva mais estimulante envolve o entendimento de que esses sentimentos são inabaláveis e compõem nossa própria constituição psicológica. Resulta, a meu ver, ocioso afirmar que o sentimento de que sou livre é ilusório, pois não temos como extirpá-lo sem com isso erradicar as bases da reponsabilidade moral. Além disso, se tal sentimento é constitutivo de nossa estrutura psicológica, não faz diferença que seja destituído de conteúdo, isto é, que não denote nada diferente dele mesmo.

\section{II}

A referência à relação entre sentimento e reponsabilidade nos conduz a um outro e instigante tópico. Refiro-me à noção de justiça eterna. De acordo com essa noção, a atribuição de responsabilidade moral ao atormentador pelos sofrimentos que causa ao atormentado prende-se a uma diferença que não atinge a coisa em si, pois algoz e vítima são unos, visto que "a vontade vive em ambos” (W I, § 63, 452). O mundo é responsável pelo próprio mundo.

Em tudo o que acontece ou pode acontecer a cada um a justiça sempre lhe é feita. Pois sua é a vontade: e tal como a vontade é, é o mundo. A responsabilidade [Verantwortlichkeit] pela existência e índole deste mundo só este mundo mesmo pode assumir; ninguém mais; pois como outrem poderia ter assumido essa responsabilidade? - Caso se queira saber, em termos morais, o que valem os humanos no todo e em geral, considere-os em seu destino no todo e em geral: trata-se de carência, miséria, penúria, tormento e morte. A justiça eterna prevalece: se os seres humanos tomados como um todo não fossem tão índigos, então o seu destino tomado como um todo não seria tão triste (W I, § 63, 449-450). 
Provavelmente será admitido por todos, sem maiores dificuldades, que tal pensamento gera um notório desconforto. Em Sobre a liberdade da vontade encontra-se a afirmação de que nos sentimos responsáveis por nosso ser, sentimento que subscreve filosoficamente a legitimidade dos juízos de louvor e censura dirigidos a indivíduos. Contudo, na passagem citada, Schopenhauer nos diz que o mundo é responsável pelo próprio mundo, o que implica uma inculpabilidade moral universal. Ora, ou a reponsabilidade individual é válida e consistente na filosofia de Schopenhauer, indo de encontro à justiça eterna, ou a justiça eterna é um desdobramento imprescindível da metafísica pessimista do autor de $O$ mundo e interdita as pretensões de justificação da responsabilidade moral dos seres humanos (entendidos, claro, no sentido de seres individuais). Diante disso, sou do parecer de que a justiça eterna não pode ser acolhida por quem queira esclarecer filosoficamente a reponsabilidade moral dos indivíduos. Outrossim, julgo que, para o autor de $O$ mundo, a justiça eterna possui proeminência metafísica de maior vulto diante da responsabilidade moral individual. Por conseguinte, sinto-me compelido a declarar que considero a tentativa de Schopenhauer de esclarecer os juízos louvor e censura morais uma tentativa frustrada. Na sequência, tentarei deixar mais clara essa posição mostrando a relevância do problema acerca da conflituosa relação entre responsabilidade moral e justiça eterna.

Preliminarmente, deve-se notar que, no I tomo de $O$ mundo, somente ao falar de justiça eterna $(\S 63)$ é que Schopenhauer se refere à reponsabilidade [Verantwortlichkeit] ${ }^{15}$. Ora, como não se trata da responsabilidade de um indivíduo pelos seus atos, mas sim de uma responsabilidade que poderia ser chamada de supra individual ou cosmológica, parece-me plenamente compreensível que se indague: como é possível atribuir responsabilidade ao um ser como o mundo, algo não individual, desprovido do sentimento de culpa?

Em apoio à pertinência desse problema, vale mencionar dois comentaristas simpáticos à causa schopenhaueriana, Ramos e Bacelar ${ }^{16}$. Ramos declara: "Sendo toda multiplicidade mera aparência, então também a responsabilização individual é ilusória: só há uma única vontade que carrega em si tanto o malumculpae como malumpoenae ${ }^{17}$. Já Bacelar tenta pensar na responsabilidade em conexão com a justiça eterna. Contudo, ele mesmo reconhece que Schopenhauer não logra êxito.

\footnotetext{
${ }^{15}$ No tomo I, nenhum esclarecimento mais expansivo é fornecido sobre a responsabilidade individual. Nem no $§ 55$ de MVR I, dedicado ao tema da liberdade, Schopenhauer desenvolve expressamente o assunto. Já no tomo II, texto posterior ao escrito Sobre a liberdade da vontade, encontramos esclarecimentos sobre a noção de responsabilidade moral.

${ }^{16}$ Digo "simpáticos à causa schopenhaueriana” usando, naturalmente, uma linguagem mais coloquial. Quero significar com isso apenas a impressão que tenho de que esses autores não pretendem desferir ataques diretos aos pilares da filosofia schopenhaueriana.

${ }^{17}$ RAMOS, F. C. A teoria da justiça de Schopenhauer, p. 183.
} 
Se a responsabilidade ou imputabilidade consiste na atribuição da autoria a uma ação criminosa que lesa uma lei clara e acarreta uma sanção, como compreender a culpa da Vontade? Nesse empreendimento de inculpação cosmológica maciça em que todos os seres por essência contraem uma dívida para com a justiça eterna anterior à existência, que será expiada nela mesma de maneira desigual, Schopenhauer ignora a contribuição de cada um na maldade do mundo. Ao não correlacionar os diferentes graus de sofrimento com os diferentes graus de culpa, Schopenhauer bloqueia, por assim dizer, a eficácia da categoria de responsabilidade pessoal pela ação ao inculpar coletivamente: todos os seres são irmanados numa essência pecaminosa que explica e justifica a maldade no mundo ${ }^{18}$.

Bacelar conclui num tom mais favorável, aludindo a uma passagem da Metafísica dos costumes em que Schopenhauer reconhece a dificuldade de compatibilizar justiça eterna e reponsabilidade moral (individual). Vale citar esse trecho: "Adicionalmente, surge a questão de como se mantém a participação de todos os homens na culpa, apesar de que a grande diversidade ética dos caracteres se mantenha em todo momento, sem enganar a consciência que incrimina um e deixa em paz o outro” (HN III, 122). Na minha opinião, contudo, essa passagem apenas indica o reconhecimento de uma dificuldade. Schopenhauer não deu uma solução para esse problema, seja descartando o conceito de justiça eterna, seja assumindo a inculpabilidade universal ${ }^{19}$.

Uma visão convergente em muitos pontos com a minha leitura de Schopenhauer encontra-se no artigo "Individualidade em sentido moral e justiça eterna”, de Orrutea Filho. O autor concorda com a ideia de que a justiça eterna não pode ser acolhida se quisermos esclarecer filosoficamente a reponsabilidade moral dos indivíduos. Corretamente Orrutea Filho percebe que "a Justiça Eterna falha miseravelmente em um ponto fundamental: ela simplesmente não parece explicar nossos juízos morais, e este é o grande objetivo da parte ética da filosofia de Schopenhauer" ${ }^{20}$. Em que pese essa concordância, o autor pretende oferecer uma interpretação que mostre que a filosofia da vontade de Schopenhauer pode dispensar a noção de justiça eterna. O comentarista

\footnotetext{
${ }^{18}$ BACELAR, A responsabilidade pela "essentia et existentia" em Schopenhauer, p. 242.

${ }^{19}$ É digno de nota que, na sequência imediata da citação acima da Metafísica dos costumes, Schopenhauer parece encolher-se para afirmar que nem tudo pode ser resolvido. "Isso se esclarecerá mais adiante, quando veremos quão estreitamente ligada ao mundo está a maldade e que o virtuoso se encontra próximo a esse último passo que conduz à redenção do mundo e suas penas. (Ademais, eu não me comprometo a solucionar todos os temas nem a responder satisfatoriamente qualquer pergunta possível; limitamo-nos a perseguir o rastro da verdade na medida de nossas possibilidades e, se a solução de muitos problemas origina alguns novos que permanecem insolúveis, isso não desfigura a vantagem que alcançamos graças a uma profunda compreensão. Dia chegara em que outros mergulhem mais profundamente ainda: multi pertransibunt et augebitur scientia [Muitos indagarão e o saber crescerá]” (HN III, 123).

${ }^{20}$ ORRUTEA FILHO, Individualidade em sentido moral e justiça eterna, p. 197.
} 
defende essa posição justamente a fim de salvar a possibilidade da compreensão schopenhaueriana dos juízos de reponsabilidade moral.

Uma alegação muito estimulante no artigo de Orrutea Filho consiste na afirmação da natureza autocontraditória da justiça eterna ${ }^{21}$. Ele afirma:

se portanto relegássemos a individualidade moral à condição de simples ilusão - como aliás, repita-se, o próprio Schopenhauer faz diversas vezes abrindo uma espécie de abismo entre individualidade e coisa-em-si, porque ausente qualquer dimensão ou elemento intermediário, o resultado seria uma compreensão segundo a qual apenas a Vontade impessoal afirma a si mesma, e os indivíduos não seriam afirmadores, mas uma espécie de objeto de afirmação desta "Vontade" terrível e cruel [...]

Portanto, para que a justiça eterna seja, afinal, justa, ela deve se referir a atores que afirmam suas vontades. Mas também sabemos, pela mesma teoria, que a vontade de cada um é a mesma que aparece em todas as coisas. Logo, o indivíduo é e não é esta vontade ao mesmo tempo, o que constitui uma contradição. Esta parece ser a base de toda a justiça eterna de Schopenhauer: uma contradição - que acreditamos refletir uma indecisão quanto às raízes metafísicas da individualidade humana ${ }^{22}$.

Ora, não há que se falar em autocontradição nesse caso, pois a responsabilidade não recai sobre o indivíduo. Isso não é de modo algum assumido por Schopenhauer. O que ele assume no $§ 63$, como já destacado, é que o mundo é responsável por tudo que acontece no mundo. Ademais, a justiça eterna não pretende ser justa no sentido da justiça temporal ou da justiça como virtude ${ }^{23}$. Note-se que, na passagem citada de MVR I, $\S 63$, Schopenhauer

21 Embora o comentarista acabe mitigando sua posição inicial. “Arriscamos dizer que, na melhor das hipóteses, a justiça eterna expressa não uma autocontradição, mas uma tensão entre elementos aparentemente contraditórios entre si, mas que na verdade se complementam (p. 194). Independente disso, para os propósitos meramente argumentativos que tenho em mira aqui, considero e rejeito apenas a possibilidade dessa suposta autocontradição.

${ }^{22}$ ORRUTEA FILHO, Individualidade em sentido moral e justiça eterna, p. 193-194.

${ }^{23}$ Para Schopenhauer, mesmo o homem bom permanece, com justiça, atado ao sofrimento por causa da justiça eterna. "De acordo com a verdade, justamente o próprio nascimento do ser humano é o ato da sua vontade livre, por consequência idêntico com o pecado original, e, assim, com a essentia e existentia do ser humano já entraria em cena o pecado original, do qual todos os demais pecados são consequência (W II, cap. 48, 720-721 - itálicos meus). Como se vê, não se trata apenas de usar o conceito de pecado original como uma alegoria proveniente do cristianismo. Embora destituído de seu conteúdo religioso, trata-se na verdade da apropriação do que talvez seja o núcleo mais significativo do conceito de pecado original, isto é, a natureza congênita e hereditária dessa excêntrica falta. Acredito que não é preciso uma demorada detenção crítica nesse ponto. Limito-me a registrar, em consonância com o que argumento acima, que, se as coisas fossem assim, nós seríamos moralmente culpados não por atos nossos, mas pela nossa simples natureza humana pecadora, o que implica dizer que seríamos simplesmente culpados por existirmos (digo pecadora aqui por carregar o erro da existência). 
se refere, com mais rigor, "aos seres humanos tomados como um todo", ao "seu destino tomado como um todo". Não se trata de indivíduos tomados em suas singularidades volitivas e morais, mas de indivíduos considerados como vontade ${ }^{24}$.

Poder-se-ia falar em contradição se o "é" e o "não é" fossem tomados no mesmo sentido $^{25}$ ou, se preferirmos, sob o mesmo aspecto. Por certo, para Schopenhauer, o indivíduo é e não é a vontade ao mesmo tempo, mas - frise-se - não sob o mesmo aspecto. Dessa forma, rigorosamente não é o caso de uma contradição, muito menos de autocontradição. Quando afirmo que o indivíduo é vontade, afirmo que o núcleo do seu ser em si não é fenomênico (num certo sentido, ele não é sequer um indivíduo, sim, isso teria de ser admitido, mas não nos leva à autocontradição). Se digo que o indivíduo não é vontade, apenas digo que ele é meramente um fenômeno (embora seja uma afirmação filosoficamente unilateral, ela não é falsa). No fundo, todo e qualquer objeto tem de ser e não ser vontade, mas sempre sob aspectos diferentes, ou seja, vontade e representação ${ }^{26}$.

Outro ponto destacado por Orrutea Filho diz respeito à incongruência entre justiça eterna e o método da filosofia de Schopenhauer. De acordo com o autor, se Schopenhauer tivesse sido fiel ao método que preconizou para sua filosofia, ele não poderia ter assumido a ideia da justiça eterna, dado ser essa uma justiça que avilta nossas intuições morais elementares ao distribuir a reponsabilidade pelo ato de agressão tanto à vítima como ao agressor $^{27}$. Não penso que seja esse o caso. Sou do parecer que Schopenhauer não comete deslize algum quando entende o livro IV de $O$ mundo como sintético. Não resultou desse método apenas a noção de justiça eterna. A exposição que se encontra no livro IV de $O$ mundo - que me seja permitida a declaração de uma trivialidade - é crucial para entendermos a íntima conexão entre a metafísica da vontade com o tema sobre o sentido e valor da existência humana, objeto desse livro (cf. W I, § 53, 353). Note-se que, nesse caso, há uma diferença importante com o escrito Sobre o fundamento da moral, pois este tem um objetivo mais restrito. Aliás, conquanto restrito, um propósito que somente pode ser

\footnotetext{
${ }^{24}$ Não pretendo, com isso, endossar o pensamento de Schopenhauer, mas apenas mostrar a não procedência da pretensão de avaliar a justiça eterna a partir de perspectivas temporais e individualizadoras.

25 “Aparência se chama representação, e nada mais: toda representação, não importa seu tipo, todo OBJETO é APARÊNCIA. Por sua vez, COISA EM SI é apenas a VONTADE: como tal não é absolutamente representação, mas toto genere diferente dela” (W I, § 21, 168). Esse ponto provavelmente faz o leitor de Schopenhauer lembrar de seus entusiasmados aplausos à conciliação entre liberdade e necessidade na filosofia de Kant. Ora, Kant padeceria da mesma dificuldade apontada por Orrutea Filho, visto que, segundo o autor da Crítica da razão pura, uma e a mesma ação é determinada por causas naturais e compreendida como livre no sentido transcendental (cf. KANT, Crítica da razão pura, A 542-558/B 570-586). Mas, como argumento acima, esse não é o caso, haja vista ser possível pensar tal conciliação como não contraditória.

${ }^{26}$ É o que está consignado no início desse texto com os abonos de W I, § 27, 203; e W I, § 71, 517.

${ }^{27}$ Com razão ele lembra de uma passagem em que Schopenhauer defende exclusivamente o método analítico para o autêntico filosofar. "Minha filosofia surgiu e se apresenta no caminho analítico, e não no sintético" (PP I, Fragmentos sobre história da filosofia, § 14, 188).
} 
atingido se penetrarmos no domínio metafísico, tal como encontrado no livro IV de $O$ mundo, o que é feito nos $\S \S$ finais, 21 e 22, de Sobre o fundamento da moral. Para Schopenhauer, portanto, o tratamento do tema acerca do fundamento da moral não pode se furtar a uma elucidação metafísica. Se uma explicação metafísica do fenômeno ético originário da compaixão pudesse ser obtida nos domínios da psicologia, não seria requerido um esclarecimento mais fundamental que exige um contato com o método sintético ${ }^{28}$.

Porém, muito mais importante que a discussão sobre qual seria o método adequado para a filosofia, é a alegação segundo a qual o entendimento de Schopenhauer sobre a justiça eterna tem implicações contraintuitivas ${ }^{29}$. Ora, antes de tudo, é preciso dizer que Schopenhauer não dá sinais de que essas implicações sejam filosofalmente corrosivas, nem que nelas haja implicações contraintuitivas ${ }^{30}$. E ele não faz isso por ter dado um passo em falso em termos metodológicos, esquecendo-se de levar em conta o entendimento moral comum ou o método analítico. O que ocorre, na verdade, é que ele não poderia reconhecer uma perturbação filosófica nesse passo sem ter reconhecido nos passos iniciais e mais essenciais de seu pensamento. Por acaso é facilmente conciliável com a compreensão comum que as pessoas têm do universo moral a tese de que nosso intelecto é servo da vontade, vontade essa entendida como ímpeto cego e esforço destituído de conhecimento? Será compatível com o entendimento comum a tese de que o teísmo é um equívoco não apenas por admitir uma transcendência indemonstrável, mas também, e sobretudo, por subtrair a reponsabilidade moral do indivíduo (cf. PP I, Fragmentos sobre história da filosofia, $\S 13,177-185)$ ? Harmoniza-se com o entendimento comum a tese de que não somos livres para agir de modo diferente do que agimos, mas apenas livres metafisicamente, isto é, livres em virtude da asseidade de nosso caráter inteligível, livres devido a um ato extratemporal da vontade? Entendo que a própria tese central de Schopenhauer, que estabelece por analogia a relação entre o micro e o macrocosmo ${ }^{31}$ e, assim, afirma ser a

\footnotetext{
${ }^{28}$ A seguinte passagem pode servir de abono ao que afirmei: "A partir de uma metafísica dada admitida como verdadeira atingir-se-ia o fundamento da ética pelo caminho sintético; assim, este seria construído a partir de baixo, e, consequentemente, a ética apresentar-se-ia apoiada firmemente. Em contrapartida, com a separação, posta nesta tarefa como necessária, entre a ética e a metafísica, nada resta senão o procedimento analítico, que parte dos fatos, quer da experiência externa, quer da consciência. Estes últimos podem, com feito, reconduzir à última raiz na mente do ser humano, a qual tem de se afirmar como fato fundamental, como fenômeno originário, sem que esse fato seja a seguir reconduzido a qualquer outra coisa. Com isso toda explicação permanece meramente psicológica” (E II, § 1, 8-9).

${ }^{29}$ Quanto a isso mantenho uma posição convergente com Orrutea Filho. Todavia, o que está em questão aqui é avaliar se esse poderia ser entendido como um problema para Schopenhauer. É justamente a respeito disso, como procuro deixar claro, que nossas visões divergem.

${ }^{30}$ Há o reconhecimento de que certa dificuldade no texto póstumo Metafísica dos costumes. Sobre isso, ver nota 20 do presente artigo.

${ }^{31}$ Sobre o tema da analogia e da relação entre o micro e o macrocosmo em Schopenhauer, vale a pena citar a excelente tese de Jorge Prado. Metafísica e ciência: a analogia da vontade entre o micro e o macrocosmo, 2019.
} 
vontade a coisa em si mesma, digo, essa tese não é uma clarificação da compreensão comum que as pessoas têm sobre suas vontades e compreensões do mundo; não é, sobretudo, uma tese congruente com nossa cosmologia intuitiva. Aliás, a filosofia para Schopenhauer visa não meramente a clarificar a experiência, mas a conferir sentido metafísico a essa experiência. "A filosofia nada é senão a compreensão correta e universal da experiência mesma, a exegese verdadeira do seu sentido e conteúdo” (W II, Cap. 17, $223)^{32}$

Cabe enfatizar que a justiça eterna é uma noção plena de significado e coerência com as premissas da metafísica de Schopenhauer. Se ele mesmo afirma que a justiça eterna reside na essência do mundo (W I, § 63, 449), poderia o leitor, em nome de uma revisão interpretativa, mas não de uma repulsa a pontos basilares do pensamento do autor que se quer interpretar, conferir outro lugar para justiça eterna, ou um não lugar, um desterro dos domínios da metafísica pessimista de Schopenhauer? Penso que não.

\section{Conclusão}

Com base no exposto nesse texto, acredito poder afirmar que Schopenhauer não logrou êxito na elucidação dos juízos de responsabilidade moral. Ele não conseguiu explicar satisfatoriamente a autocompreensão que o sujeito moral tem sobre ser capaz de agir de modo diferente (seja esse um sentimento ilusório ou não). Tampouco foi capaz de explicar como podemos nos compreender como seres que são autores de sua própria existência moral, visto que deixa envolta numa espessa neblina as noções básicas de escolha e decisão, subtraindo destas o elemento epistêmico que me parece necessário. Outrossim, a justiça eterna, noção cara à metafísica pessimista de Schopenhauer, não pode ser compatibilizada com os requerimentos individualizadores da responsabilidade moral. A adoção de um procedimento arbitrário de excisão da justiça eterna poderia restituir dignidade filosófica aos juízos de louvor e censura morais, mas, nesse caso, teríamos de abandonar a imagem de um filósofo que pretende comunicar um pensamento único.

UM PENSAMENTO ÚNICO, por mais abrangente que seja, guarda a mais perfeita unidade. Se, todavia, em vista de sua comunicação, é decomposto em partes, então a coesão destas tem de ser, por sua vez, orgânica, isto é, tal em que cada parte tanto conserva o todo quanto é por ele conservada, nenhuma é a primeira ou a última, o todo ganha em clareza mediante cada parte, e a

\footnotetext{
${ }^{32}$ Logo na sequência se lê que a metafísica "jamais se afasta por completo da experiência, mas permanece a simples interpretação e exegese desta, já que nada fala da coisa em si senão em sua referência à aparência" (W II, Cap. 17, 223). Outra afirmação análoga: "Em verdade, a tarefa da metafísica não é a observação de experiências singulares, mas sim a explicação correta da experiência em seu todo. O fundamento da metafísica, portanto, tem de ser de tipo empírico” (W II, Cap. 17, 220)
} 
menor parte não pode ser plenamente compreendida sem que o todo já o tenha sido previamente (W I, 19-20).

A questão sobre se Schopenhauer obtém êxito em preservar uma coesão orgânica, salvaguardando assim a mais perfeita unidade ao pensamento único, foge do escopo desse texto. Porém, acredito que a reposta negativa dada aqui à sua tentativa de elucidar os juízos de imputação moral responde, de modo parcial e indireto, também à questão sobre a perfeita unidade de seu pensamento único. Responde, por certo, de modo igualmente negativo.

\section{Referências}

BACELAR, K. A responsabilidade pela essentia et existentia em Schopenhauer. In: DEBONA, Vilmar; FONSECA, Eduardo Ribeiro da; HULSHOF, Monique; MATTOS, Fernando da Costa; RAMOS, Flamarion Caldeira (Orgs.). Dogmatismo e antidogmatismo: filosofia crítica, vontade e liberdade. Uma homenagem a Maria Lúcia Cacciola. Curitiba: Editora UFPR, 2015, p. 225-242.

DEBONA, Vilmar. Caráter, liberdade e Aseität: sobre a assimilação das noções de caráter inteligível e caráter empírico de Kant por Schopenhauer. Kant e-Prints, Campinas, 11(2), 32$50,2016$.

HOBBES, T. Leviathan. Edição J. C. A Gaskin. Oxford University Press (Oxford World's Classics), 1996.

HOBBES, Thomas. Hobbes's Treatise of Liberty and Necessity. In: Hobbes and Bramhall on Liberty and Necessity. Edição Vere Chappell. Cambridge University Press, 1999.

HUME, D. A Treatise of Human Nature. Volume 1: Texts. A critical edition. Ed. D. F. Norton \& M. J. Norton. Oxford: University Press, 2011.

HUME, D. An Enquiry concerning Human Understanding. Ed. Tom L. Beauchamp. Oxford: University Press, 1999.

KANT, I. Crítica da razão pura. Trad. Manuela Pinto dos Santos e Alexandre Fradique Morujão. Lisboa: Fundação Calouste Gulbenkian, 1994.

KANT, I. Metafísica dos Costumes. Trad. Clélia Aparecida Martins, Bruno Nadai, Diego Kosbiau e Monique Hulshof. Petrópolis: Vozes; Bragança Paulista: Editora Universitária São Francisco, 2013.

ORRUTEA FILHO, Rogério Moreira. Sobre a distinção entre individualidade moral e individuação corpórea em Schopenhauer. In: PAVÃO, Aguinaldo; FELDHAUS, Charles; 
WEBER, José Fernandes. (Org.). Schopenhauer: metafísica e moral. São Paulo: DWW Editorial, 2014, p. 155-188.

ORRUTEA FILHO, Rogério Moreira. Individualidade em sentido moral e justiça eterna. Voluntas: Revista Internacional de Filosofia, Santa Maria, v. 10, n. 1, p. 186-198, jan./abr. 2019.

PAVÃO, Aguinaldo. Kant e Schopenhauer sobre a natureza da filosofia moral. Dissertatio (UFPel), v. 30, p. 135-148, 2009.

PAVÃO, Aguinaldo: Liberdade e imputação moral em Schopenhauer. In: PAVÃO, Aguinaldo; FELDHAUS, Charles; WEBER, José Fernandes. (Org.). Schopenhauer: metafísica e moral. São Paulo: DWW Editorial, 2014, p. 91-110.

PRADO, Jorge Luis Palicer do. Metafísica e ciência: a analogia da vontade entre o micro e o macrocosmo. Tese de Doutorado em Filosofia, Universidade de São Paulo, São Paulo, 2019.

RAMOS, F. C. A teoria da justiça de Schopenhauer. Ethic@, Florianópolis, v. 11, n. 2, p. 173-185, julho de 2012.

SCHOPENHAUER, A. Fragmentos sobre história da filosofia. Trad. Karina Jannini. São Paulo: Martins Fontes, 2007.

SCHOPENHAUER, A. Sobre a vontade na natureza. Trad. Gabriel Valladão Silva. Porto Alegre: L\&PM, 2013.

SCHOPENHAUER, Arthur. Prize essay on the freedom of the will. In: The two fundamental problems of ethics. Trad. Christopher Janaway. New York: Cambridge University Press, 2009.

SCHOPENHAUER, Arthur. Die Welt als Wille und Vorstellung. Erster Band. Werke in zehn Bänden. Band II. Zürich: Diogenes Verlag, 1977.

SCHOPENHAUER, Arthur. Metafísica de las costumbres. Trad. Roberto Rodríguez Aramayo. Madrid: Trotta, 2001.

SCHOPENHAUER, Arthur. O mundo como vontade e como representação. Tomo I. Trad. Jair Barboza. São Paulo: Unesp, 2005.

SCHOPENHAUER, Arthur. O mundo como vontade e como representação. Tomo II: Suplementos aos quatro livros do primeiro tomo. Trad. Jair Barboza. São Paulo: Unesp, 2015.

SCHOPENHAUER, Arthur. Parerga e Paralipomena (cap. V, VIII, XII, XIV). Trad. Wolfang Leo Maar. São Paulo: Nova Cultural, 1988 (Os Pensadores).

SCHOPENHAUER, Arthur. Parerga und Paralipomena: kleine philosophische Schriften. Zweiter Band. Diogenes Verlag AG Zürich, 1977. 
SCHOPENHAUER, Arthur. Sobre a ética. Trad. Flamarion C. Ramos. São Paulo: Hedra, 2012.

SCHOPENHAUER, Arthur. Sobre a filosofia e seu método. Trad. Flamarion C. Ramos. São Paulo: Hedra, 2010.

SCHOPENHAUER, Arthur. Sobre o fundamento da moral. Trad. Maria Lúcia Cacciola. São Paulo: Martins Fontes, 1995.

SCHOPENHAUER, Arthur. Über die Grundlage der Moral. Kleinere Schriften. Sämtliche Werke, Band III: Bearbeitet und Heraugegebt von Wolfgang Frhr. Von Löhnheysen. Frankfurt am Main: Suhrkamp, 1998, p. 629-815. 